\title{
Application of a regularized model inversion system (REGFLEC) to multi-temporal RapidEye imagery for retrieving vegetation characteristics
}

\author{
Rasmus Houborg*a, Matthew F. McCabe ${ }^{\mathrm{b}}$ \\ ${ }^{a}$ Water Desalination and Reuse Center, Biological and Environmental Sciences and Engineering \\ Division, King Abdullah University of Science and Technology (KAUST), Saudi Arabia
}

\begin{abstract}
Accurate retrieval of canopy biophysical and leaf biochemical constituents from space observations is critical to diagnosing the functioning and condition of vegetation canopies across spatio-temporal scales. Retrieved vegetation characteristics may serve as important inputs to precision farming applications and as constraints in spatially and temporally distributed model simulations of water and carbon exchange processes. However significant challenges remain in the translation of composite remote sensing signals into useful biochemical, physiological or structural quantities and treatment of confounding factors in spectrum-trait relations. Bands in the red-edge spectrum have particular potential for improving the robustness of retrieved vegetation properties. The development of observationally based vegetation retrieval capacities, effectively constrained by the enhanced information content afforded by bands in the red-edge, is a needed investment towards optimizing the benefit of current and future satellite sensor systems. In this study, a REGularized canopy reFLECtance model (REGFLEC) for joint leaf chlorophyll $\left(\mathrm{Chl}_{1}\right)$ and leaf area index (LAI) retrieval is extended to sensor systems with a band in the red-edge region for the first time. Application to time-series of $5 \mathrm{~m}$ resolution multi-spectral RapidEye data is demonstrated over an irrigated agricultural region in central Saudi Arabia, showcasing the value of satellite-derived crop information at this fine scale for precision management. Validation against in-situ measurements in fields of alfalfa, Rhodes grass, carrot and maize indicate improved accuracy of retrieved vegetation properties when exploiting red-edge information in the model inversion process.
\end{abstract}

Keywords: LAI, leaf chlorophyll, REGFLEC, RapidEye, red-edge

\section{INTRODUCTION}

Remote sensing of important plant biochemical and biophysical quantities such as leaf chlorophyll content $\left(\mathrm{Chl}_{1}\right)$ and leaf area index (LAI) has seen significant advances over the past half-century with developments in remote sensor technologies and the capacity to retrieve vegetation traits from composite surface reflectance fields ${ }^{1}$. These biophysical quantities are useful for monitoring and characterizing vegetation density and health and can serve as important observational constraints in model simulations of terrestrial surface fluxes in space and time domains ${ }^{2,3}$. Precision farming represents an important application of remote sensing fields, as remote sensors can provide the spatially and temporally distributed information needed for detecting within field variability in crop condition and health related to nutrient and water limitation, heat stress or pest infestation. Such information is key to defining spatially explicit strategies for optimizing yield, while minimizing water and fertilizer application ${ }^{4}$. Remote sensing provides the only realistic tool through which to gain such information.

The utility of remote sensing for precision agriculture has traditionally been constrained by the low spatial, temporal or spectral resolution of available satellite sensors ${ }^{5}$. With the era (1999-) of commercially available very high resolution $(<10 \mathrm{~m})$ multi-spectral satellite systems, some of these limitations have been overcome. For example, the RapidEye (2008-) and WorldView (2009-) series of satellites provide pixel resolutions of between 2-5 m, frequent revisit times, and enhancements to spectral monitoring with band(s) in the red-edge spectrum. Bands in the red-edge are important for estimating plant traits related to leaf biochemistry and photosynthetic processes such as $\mathrm{Chl}_{1}{ }^{6-8}$, which is of particular interest in precision farming applications ${ }^{9}$. However, the full potential of these well-equipped sensor designs for 
precision monitoring has yet to be realized, in part as a result of the prohibitive image acquisition costs. The pair of Sentinel-2 satellites from the European Space Agency (S2-A was successfully launched June $23^{\text {rd }}$, 2015) will deliver (free of charge) multi-spectral data (incl. 2 narrow bands in the red-edge domain) at resolutions down to $10 \mathrm{~m}$ and with a revisit capability of $\sim 5$ days (once both satellites are in orbit). This sensor design has the opportunity to significantly advance fine resolution mapping of vegetation state and function routinely and globally at no cost.

While the current space-based Earth observation capacity is advanced, challenges remain in the treatment of confounding factors in spectrum-trait relationships, particularly in the translation of composite remote sensing signals into useful biochemical, physiological or structural quantities required to characterize vegetation canopies ${ }^{8}$. The inversion of a canopy radiative transfer model is ill-posed by nature, as different combinations of vegetation model parameters can produce almost identical spectra, resulting in non-unique solutions ${ }^{10}$. Approaches based on physical principles are essential for ensuring extendibility in space and time and applicability over a diversity of crop types and surface and atmospheric conditions $s^{11,12}$. Regularization strategies ${ }^{13-15}$ have proven effective at improving the robustness and accuracy of retrieved properties, by increasing the amount of information used in the inversion process. This may be achieved in the form of additional spectral bands with optimized sensitivity to parameters of interest, constraints based on spatial and temporal patterns, prior information, and ancillary data from alternative sources.

In this contribution, the regularized canopy reflectance model, REGFLEC ${ }^{15}$ is extended to sensor systems with a band in the red-edge region for the first time, in order to capitalize on the improved sensitivity of red-edge bands over the full range of chlorophyll values and reduced sensitivity to confounding factors. REGFLEC represents a fully integrated system of radiative transfer models that can be applied over a diversity of land cover types, soil backgrounds and atmospheric conditions based on image-based methodologies, thereby removing the need for site-specific calibration. REGFLEC implements novel spatio-temporal constraints and ancillary information within a multi-step look-up table inversion approach in an attempt to mitigate the ill-posed inverse problem and properly discriminate contributions from the atmosphere, canopy and soil. This scheme has demonstrated potential for joint $\mathrm{Chl}_{1}$ and LAI retrieval using multispectral operational sensor systems with standard broad bands in the green, red and near-infrared ${ }^{16,17}$ although the limited radiometric information content carried by these sensors pose some challenges ${ }^{15}$. The red-edge refinement presented here applies to RapidEye satellite data collected over a desert agricultural region in Saudi Arabia. Model performances of retrieved LAI and $\mathrm{Chl}_{1}$ are evaluated against in-situ measurements in fields of alfalfa, Rhodes grass, carrot and maize over different plant development stages. The study identifies optimal integration of red-edge information within REGFLEC and assesses improvements in retrieval accuracy from utilizing the enhanced radiometric information content constituted by the additional band in the red-edge region.

\section{MATERIAL AND METHODS}

\subsection{Study site}

The Tawdeehiya Arable Farm $\left(24.174^{\circ} \mathrm{N}, 48.015^{\circ} \mathrm{E}\right)$ is located in the desert region of Al-Kharj, southeast of the capitol Riyadh in Saudi Arabia (Figure 1). This industrial scale commercial farm operates 47 fields with center-pivot irrigation systems (diameter $\sim 1 \mathrm{~km}$ ). Key crops under irrigation include alfalfa, Rhodes grass, maize and carrots. The region is characterized by an extreme desert climate with hot summer months (average high $=43^{\circ} \mathrm{C}$ ) and an average annual precipitation total of $95 \mathrm{~mm}$ concentrated during the months of December through April ${ }^{18}$. The Hydrology and Land Observation (HALO) group at King Abdullah University of Science and Technology (KAUST) has recently established a state-of-the-art observatory at the Tawdeehiya Arable Farm, deploying flux and meteorological towers and a wide range of soil, vegetation and UAV (unmanned aerial vehicles) based sensors. This study uses data collected during three intensive field campaigns that took place between March 22 - March 25, April 12 - April 16, and May 31 - June 4, respectively, covering plant development stages from green-up through reproduction of the four crops. 


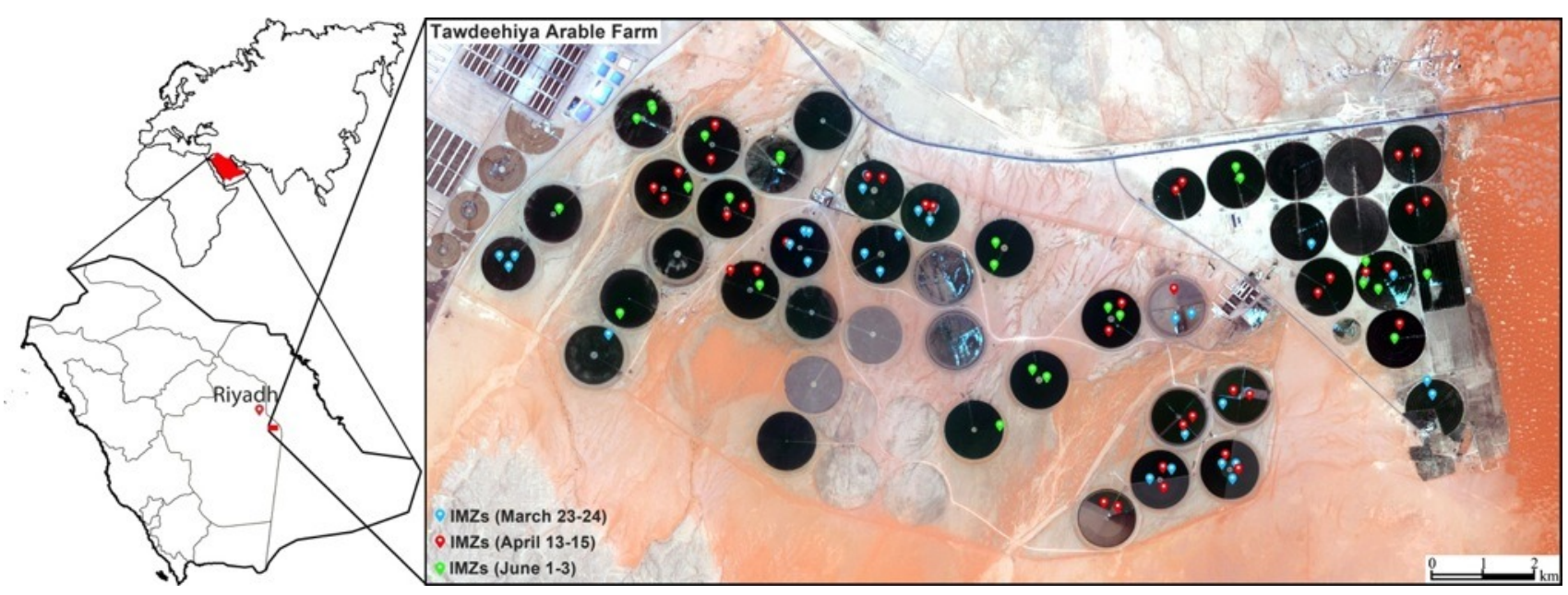

Figure 1. Location map of the Tawdeehiya Arabla Farm in Saudi Arabia. The sites of intensive measurements during the three field campaigns in 2015 are indicated on the imagery. The image is a natural color representation of $5 \mathrm{~m}$ resolution RapidEye data collected on May $31^{\text {st }}$.

\subsection{In-situ measurements}

During each of the campaigns, non-destructive sampling of biophysical properties was conducted within small $(10 \times 10$ $\mathrm{m}$ ) intensive measurement zones (IMZ) established in relatively homogeneous sections of the fields (Figure 1). Specific attention was given to LAI, defined as one-sided green leaf area per unit horizontal ground area $\left[\mathrm{m}^{-2} \mathrm{~m}^{-2}\right]$, and $\mathrm{Chl}_{1}$, defined as the total chlorophyll $a$ plus chlorophyll $b$ content on a one-sided leaf area basis $\left[\mu \mathrm{g} \mathrm{cm}^{-2}\right]$. Within each IMZ a grid of five plots were defined and measurements at each plot were averaged to achieve a representative value for that specific IMZ. LAI was measured using a LAI-2200C plant canopy analyzer (LICOR, U.S.A.) using a $270^{\circ}$ view cap to avoid interferences caused by the operator. At each plot, one above-canopy and four below-canopy readings were conducted and repeated once. For the row crops (maize and carrots), the four below-canopy readings were done along diagonal transects between the rows to better approximate the 'true' (i.e., from destructive sampling) LAI ${ }^{19}$. Thus in each IMZ, the average of five LAI-2200C measurements (5 x 8 readings) was used. Measurements were conducted throughout the day on clear days and corrected for light scattering ${ }^{20}$ to avoid underestimation of LAI for data taken in direct sun. $\mathrm{Chl}_{1}$ was measured simultaneously with a portable SPAD-502 meter (Konica Minolta, Inc., Osaka, Japan). In maize, SPAD readings were taken at six locations on each leaf and averaged, and the procedure repeated for a total of four leaves (top-most) at each sampling plot, and the resulting 5 x 4 measurements (i.e., 5 x 24 readings) were averaged over the IMZ. For alfalfa and Rhodes grass, five SPAD readings taken on random leaves were averaged and repeated five times on different leaves within each sampling plot to produce a single IMZ representative value based on a total of $5 \times 5$ measurements (i.e., 5 x 25 readings). The non-dimensional SPAD units $(0-99)$ were converted to actual leaf chlorophyll content in units of $\mu \mathrm{g} \mathrm{cm}^{-2}$ using a calibration curve $\left(\mathrm{Chl}_{1}=87.889 \exp [0.0103 \mathrm{SPAD}]-92.911, \mathrm{r}^{2}=0.93\right.$, $\mathrm{rmsd}=4.9 \mu \mathrm{g} \mathrm{cm}^{-2}$ ) derived on the basis of a spectrophotometrical analysis of multi-species agricultural leaf samples ${ }^{16}$. This calibration closely resembles $\left(\mathrm{r}^{2}=0.99, \mathrm{rmsd}=2.4 \mu \mathrm{g} \mathrm{cm}{ }^{-2}\right)$ the transformation equation $\left(\mathrm{Chl}_{1}=[99 \mathrm{SPAD}] /[144-\right.$ $\mathrm{SPAD}]$ ) derived based on a compilation of eight different calibration models ${ }^{21}$, which suggests reasonable utility in using a single calibration curve irrespective of species type and SPAD sensor unit. The outlined measurement protocols were completed for a total of $96 \mathrm{IMZs}$ over the duration of the three campaigns.

\subsection{RapidEye data}

RapidEye constitutes a five-satellite constellation with identical multi-spectral sensors collecting imagery at $5 \mathrm{~m}$ resolution in blue $(440-510 \mathrm{~nm})$, green $(510-590 \mathrm{~nm})$, red $(630-690 \mathrm{~nm})$, red-edge $(685-735 \mathrm{~nm})$ and near-infrared $(750-$ $860 \mathrm{~nm})$ spectral bands. In this study, RapidEye level 3A data were provided radiometrically calibrated and orthorectified by BlackBridge (www.blackbridge.com) on day of year (DOY) 87 (March 28), 102 (April 12) and 151 (May 31), within $2-5$ days of the in-situ data collections. The acquisitions occurred between 11:14 am and 11:28 am local time with sensor view zenith angles of $16.9^{\circ}, 12.8^{\circ}$ and $3.2^{\circ}$, respectively. 


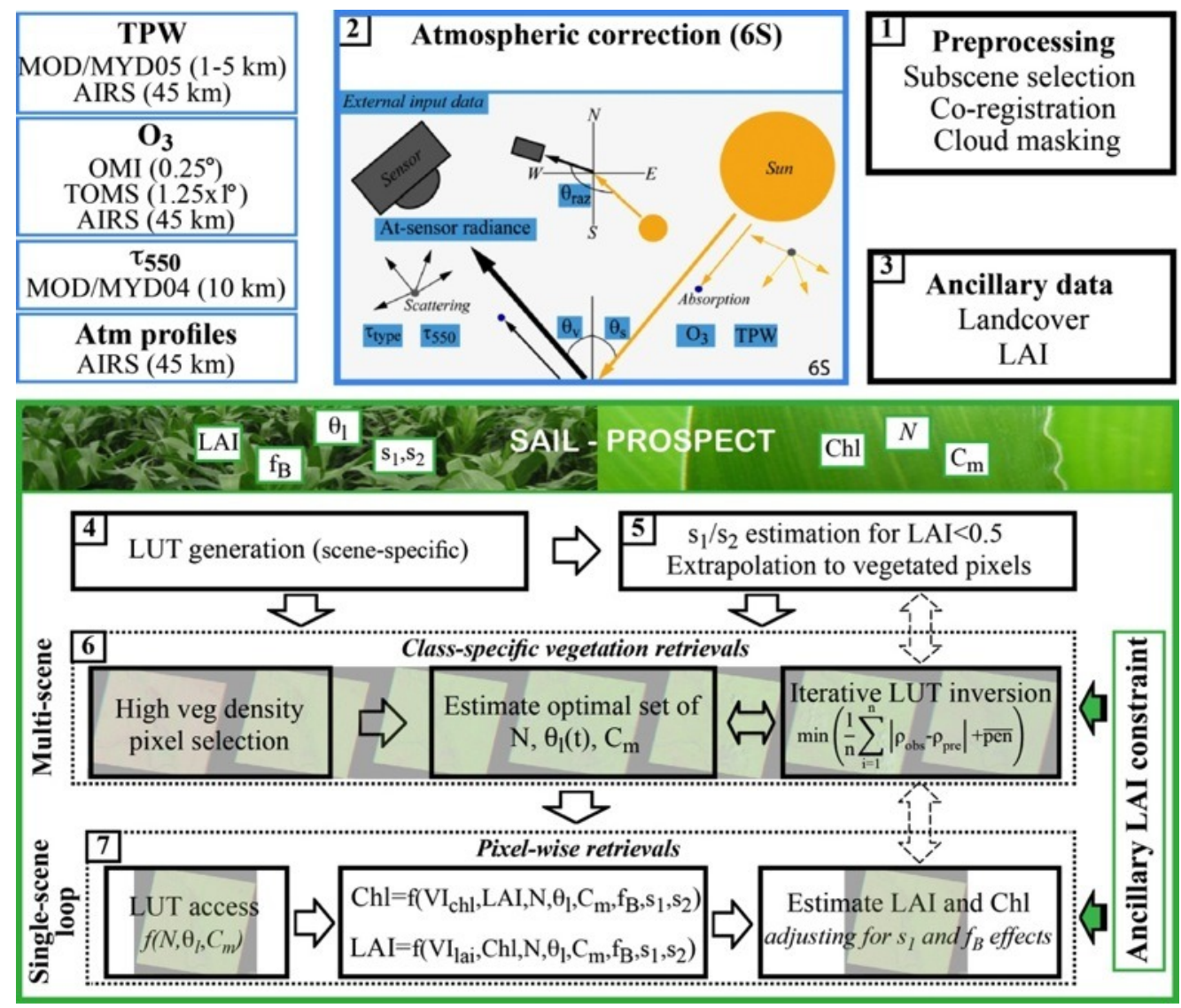

Figure 2. Schematic overview of the processing steps implemented in the REGFLEC retrieval system. REGFLEC combines atmospheric (6S), canopy (SAIL) and leaf (PROSPECT) models in an iterative LUT-based inversion approach for the translation of at-sensor radiances into vegetation biophysical properties. In the provided minimization function (used in both step 5,6 and 7), $\mathrm{p}_{\mathrm{obs}}$ and $\mathrm{p}_{\text {pre }}$ represent observed and modeled spectral reflectances, respectively and pen is a penalty operator. In step 7, the vegetation index used for mapping leaf chlorophyll $\left(\mathrm{VI}_{\mathrm{chl}}\right)$ and leaf area index $\left(\mathrm{VI}_{\mathrm{LAI}}\right)$ depends on the spectral characteristics of the sensor. See Sections 2.3 and 2.4 for parameter definitions. Detailed methodology is given in ${ }^{2}$.

The at-sensor multi-spectral radiances were atmospherically corrected to bidirectional surface reflectances using the vector version of the Second Simulation of the Satellite Signal in the Solar Spectrum, $6 \mathrm{~S}^{22}$ atmospheric radiative transfer model following the automated processing stream implemented in REGFLEC ${ }^{15}$. Accordingly, spatially distributed information on aerosol optical depth at $550 \mathrm{~nm}\left(\tau_{550}\right)$, total precipitable water (TPW), and total ozone content $\left(\mathrm{O}_{3}\right)$ was acquired from the Terra MODIS aerosol product (MOD04), the Terra MODIS water vapor product (MOD05), and the Aura Ozone Monitoring Instrument (OMI), respectively. Vertical profiles of temperature, humidity and ozone were taken from the Aqua AIRS standard product and the aerosol type and profile was assumed from a background desert aerosol model ${ }^{23}$. The scene-averaged aerosol loadings $\left(\tau_{550}=0.41,0.60\right.$, and 0.27$)$ and TPW values $(2.8,2.2$, and $1.5 \mathrm{~g}$ $\mathrm{cm}^{-2}$ ) derived from Terra MODIS were found to be in good agreement with time-simultaneous sun photometer measurements from the Solar Village Aerosol Robotic Network (AERONET) site $\left(24.91^{\circ} \mathrm{N}, 46.41^{\circ} \mathrm{E}\right)$, located immediately west of Riyadh in a rural agricultural setting. The atmospheric correction also included corrections for adjacency effects, which are particularly important for high spatial resolution observations in regions with large contrasts in surface reflectance ${ }^{24}$.

\subsection{LAI and $\mathrm{Chl}_{1}$ retrieval approach}

The Regularized Canopy Reflectance model $\left(\right.$ REGFLEC $\left.^{15}\right)$ constitutes a multi-step vegetation retrieval and regularization methodology (Figure 2 ) integrating atmospheric radiative transfer $\left(6 \mathrm{~S}^{25}\right)$, canopy reflectance $\left(4 \mathrm{SAIL}^{26,27}\right)$ 
and leaf optical (PROSPECT ${ }^{28,29}$ ) models. The Scattering by Arbitrary Inclined Leaves model, 4SAIL, is used to calculate bidirectional canopy reflectance over relevant sensor-specific spectral bandwidths given inputs of observation geometry, LAI, mean leaf inclination angle $\left(\theta_{1}\right)$, two soil parameters $\left(s_{1}\right.$ and $\left.s_{2}\right)$, canopy fraction of senescent leaf material $\left(\mathrm{f}_{\mathrm{B}}\right)$, a hot spot parameter $\left(\mathrm{s}_{\mathrm{L}}\right)$, the fraction of diffuse radiation calculated as a function of $\tau_{550}$, and leaf reflectance and transmittance. Leaf reflectance and transmittance spectra are simulated by PROSPECT with inputs of a leaf mesophyll structure parameter $(N), \mathrm{Chl}_{\mathrm{l}}$, equivalent water thickness $\left(\mathrm{C}_{\mathrm{w}}\right)$, dry matter content $\left(\mathrm{C}_{\mathrm{m}}\right)$, and leaf brown pigments $\left(\mathrm{C}_{\mathrm{bp}}\right)$.

The fundamental innovation of REGFLEC lies in its use of image-based regularization strategies (i.e., constraints) for building a suite of predictive (LAI and $\mathrm{Chl}_{1}$ ) Vegetation Index (VI) relationships that consider spatio-temporal variations in plant biochemistry, structure and biomass, soil background, atmospheric condition, and viewing and illumination geometry without relying on impractical site-specific calibration. Careful attention to confounding factors in spectrumtrait relations is critical in order to improve the robustness and accuracy of retrieved properties and better discriminate between atmospheric, soil, canopy and leaf contributions to the satellite observed reflectance field. For this purpose, REGFLEC embeds a multi-step Look-Up-Table (LUT) based inversion scheme (Figure 2) that 1) attempts to reduce obfuscating influences of the soil background signal on the vegetation retrievals by estimating representative ranges of $s_{1}$ and $s_{2}$ during sparse vegetation coverage, and 2) retrieves optimal sets of class-invariant vegetation parameters based on spectral observations over intermediate to dense vegetation from multiple scenes available over a growing season. In the process of matching measured and modeled LUT spectra, and finding the optimal parameter combination (i.e., LAI, Chl, $\mathrm{N}, \theta_{1}, \mathrm{f}_{\mathrm{B}}, \mathrm{C}_{\mathrm{m}}, \mathrm{s}_{1}$, and $\mathrm{s}_{2}$ ), soil and class-specific vegetation parameters are retrieved separately (step 5 and 6 ) before mapping LAI and $\mathrm{Chl}_{1}$ over the modeling domain (step 7). The derivation of the optimal solutions is also affected by assigned penalties (e.g. for out of range conditions) ${ }^{16}$ and the LUT inversion is iterative in that the minimization function (Figure 2) is evaluated for a range of plausible parameter combinations, by using the LUTs in both forward and inverse model for estimating $\mathrm{LAI} / \mathrm{Chl}_{1}$ and reflectances ${ }^{15}$. This approach is less sensitive to the chosen LUT parameter distribution space and facilitates effective use of spatial and temporal constraints and ancillary information ${ }^{15}$.

This scheme has demonstrated potential for joint $\mathrm{Ch}_{1}$ and $\mathrm{LAI}$ retrieval using multi-spectral operational sensor systems with standard broad bands in the green, red and near-infrared ${ }^{16,17}$. In these applications, REGFLEC was configured to use green band $\left(\mathrm{R}_{\text {gre }}\right)$ relationships for $\mathrm{Chl}_{1}$ prediction. In this study, REGFLEC is extended to include a band in the red-edge region in an effort to further improve the chlorophyll retrieval capacity. The MERIS Terrestrial Chlorophyll Index, MTCI (Dash and Curran, 2007) has demonstrated greater linearity and improved sensitivity over the full range of Chl values, and is adopted here using the spectral configuration of the RapidEye sensor (i.e., $M T C I=\left[R_{\text {nir }}-R_{\text {redge }}\right] /\left[R_{\text {redge }}-R_{\text {red }}\right]$ ). The implications of using MTCI in place of $\mathrm{R}_{\mathrm{gre}}$ as predictor of $\mathrm{Chl}_{1}$ within the framework of REGFLEC will be shown and discussed in Section 3.

\subsection{REGFLEC setup}

REGFLEC was setup to run in two different modes: 1) standard mode with RapidEye bands in green, red and nearinfrared and 2) red-edge mode with an additional band in the red-edge. LUTs were generated for the four spectral bands as well as indices dedicated for $\mathrm{Chl}_{1}$ (i.e., MTCI) and LAI prediction. The two-band enhanced vegetation index, EVI2 ${ }^{30}$ is used as the primary LAI predictor in the standard mode in place of the three-band $\mathrm{EVI}^{31}$ due to large uncertainties associated with the blue band ${ }^{15}$. In the red-edge mode, the red-edge ratio $\left(\mathrm{CI}_{\text {redge }}=\mathrm{R}_{\text {nir }} / \mathrm{R}_{\text {redge }}\right)$ is adopted for LAI prediction to exploit its improved predictability over dense vegetation ${ }^{32}$. These LUTs were computed using a wide parameter distribution space as detailed in ${ }^{15}$.

REGFLEC requires accurate separation of individual land cover classes in order to effectively complete the classspecific retrieval process (Figure 2). Information on the actual cover types is however not required. In this study, the land cover map was established based on visual inspection of the cover types during the field campaigns resulting in four classes to represent the four agricultural crops (alfalfa, Rhodes grass, carrots and maize). 
a)

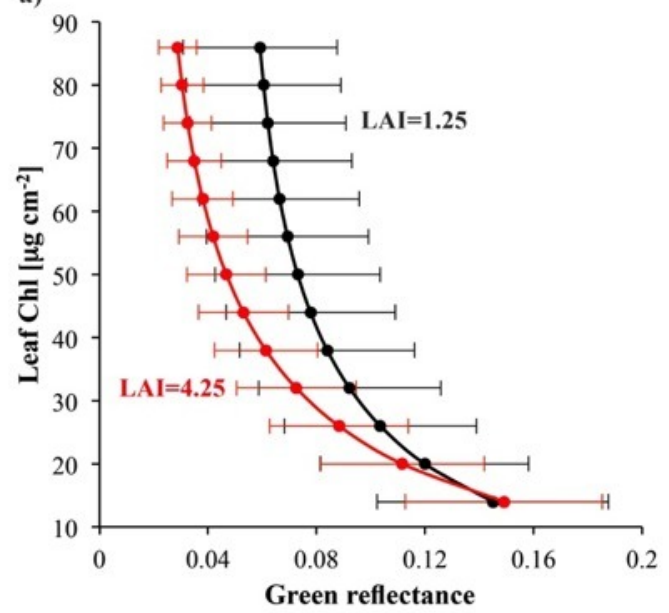

b)

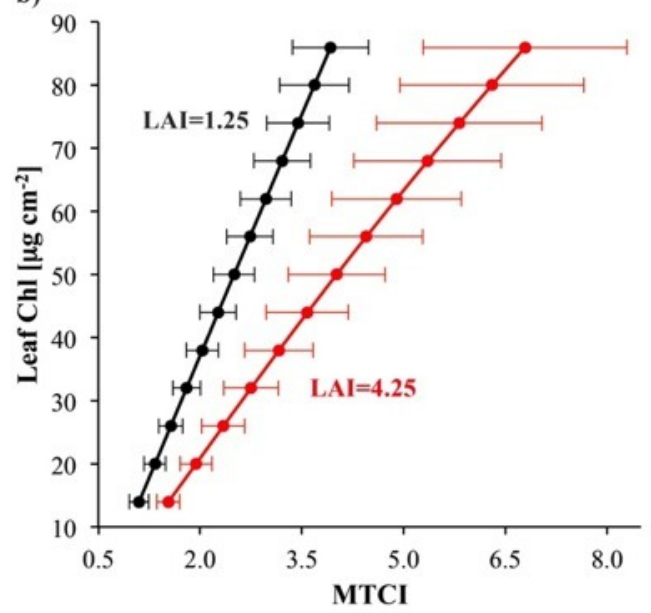

Figure 3. Model (SAIL-PROSPECT) generated (a) leaf chlorophyll-green reflectance and (b) leaf chlorophyll-MTCI relationships based on the spectral bands of RapidEye. The two LAI specific relationships represent the average of multiple simulations with changing leaf structure $(N=1-2)$, leaf inclination angle $\left(\theta_{\mathrm{l}}=35-65^{\circ}\right)$ and soil background (bright to dark) and a fixed viewing and illumination geometry.

Leaf and canopy biophysical properties can have a mutually compensating effect on canopy reflectance, and the use of ancillary LAI within the REGFLEC inversion scheme (Figure 2) has been shown to be an important regularization constraint for better discriminating LAI and $\mathrm{Chl}_{1}$ effects on observed reflectance spectra ${ }^{15}$. In this study, the ancillary LAI data was retrieved from the RapidEye spectral data using rule-based multi-variate regression models established by Cubist (RuleQuest; www.rulequest.com). Cubist represents a data mining approach for identifying effective predictive models on the basis of a training dataset of observed target and explanatory variables. The training dataset consisted of the in-situ collected LAI (Section 2.2) from the three field campaigns, which were paired with appropriate explanatory spectral bands and VIs extracted from the RapidEye imagery within 2-5 days of the in-situ collections. The majority of the training cases $(n=81)$ were described by a single rule $\left(\mathrm{LAI}=-8.18 \mathrm{e}^{-2}+1.72 \mathrm{CI}_{\text {redge }}-4.78 \mathrm{NDVI}+\mathrm{R}_{\mathrm{nir}}-0.45 \mathrm{EVI} 2-\right.$ $0.8 \mathrm{R}_{\mathrm{red}}$ ) that was predominantly used to map LAI over the full extent of the imagery. Evaluation of the regression models against the same training dataset yielded an error of 0.24 and a Pearson's correlation coefficient of 0.94 . The resulting LAI maps serve to initialize the inversion process and better constrain the retrieval of class-specific parameters $\left(N, \theta_{1}\right.$, $\mathrm{C}_{\mathrm{m}}$ ), and provide an informed basis for simultaneous retrieval of $\mathrm{LAI}$ and $\mathrm{Ch}_{1}{ }^{15}$.

\section{RESULTS AND DISCUSSION}

REGFLEC was configured to run in standard and red-edge mode using model simulated green reflectance $\left(\mathrm{R}_{\mathrm{gre}}\right)$ and MTCI relationships, respectively for the prediction of $\mathrm{Chl}_{1}$. Model simulations with SAIL-PROSPECT over a wide parameter distribution space show a significant response of $\mathrm{R}_{\text {gre }}$ to changes in $\mathrm{Ch}_{1}$ with a saturation trend at intermediate to high values of $\mathrm{Chl}_{1}$ (Figure 3a). Combined with significant sensitivity to changing leaf structure, leaf angle, and soil background conditions (as indicated by the error bars) as well as LAI over the full range of chlorophyll values (Figure $3 a)$, proper discrimination and quantification of these model parameters is critical for accurate estimation of $\mathrm{Chl}_{1}$ from $\mathrm{R}_{\text {gre }}$ relationships. MTCI shows greater linearity with improved sensitivity over the full range of $\mathrm{Chl}_{1}$ values (Figure $3 \mathrm{~b}$ ). The index normalization reduces the effect of confounding factors, particularly at the lower $\mathrm{Chl}_{1}$ range, but a strong dependence on LAI is also evident (Figure 3b).

Figure 4 intercompares retrievals of LAI and $\mathrm{Chl}_{1}$ based on standard and red-edge configured REGFLEC runs over a section of the study area during the final field campaign (May $31^{\text {st }}$ ). The derived LAI maps display fine-scale spatial features in vegetation density such as those affected by pivot irrigation trenches and patchy vegetation conditions, which demonstrate the potential of satellite-derived information at this fine spatial scale (i.e., $5 \mathrm{~m}$ ) for agricultural decision support and management purposes. During this time the fields were mostly in the vegetative stage with LAI close to the 

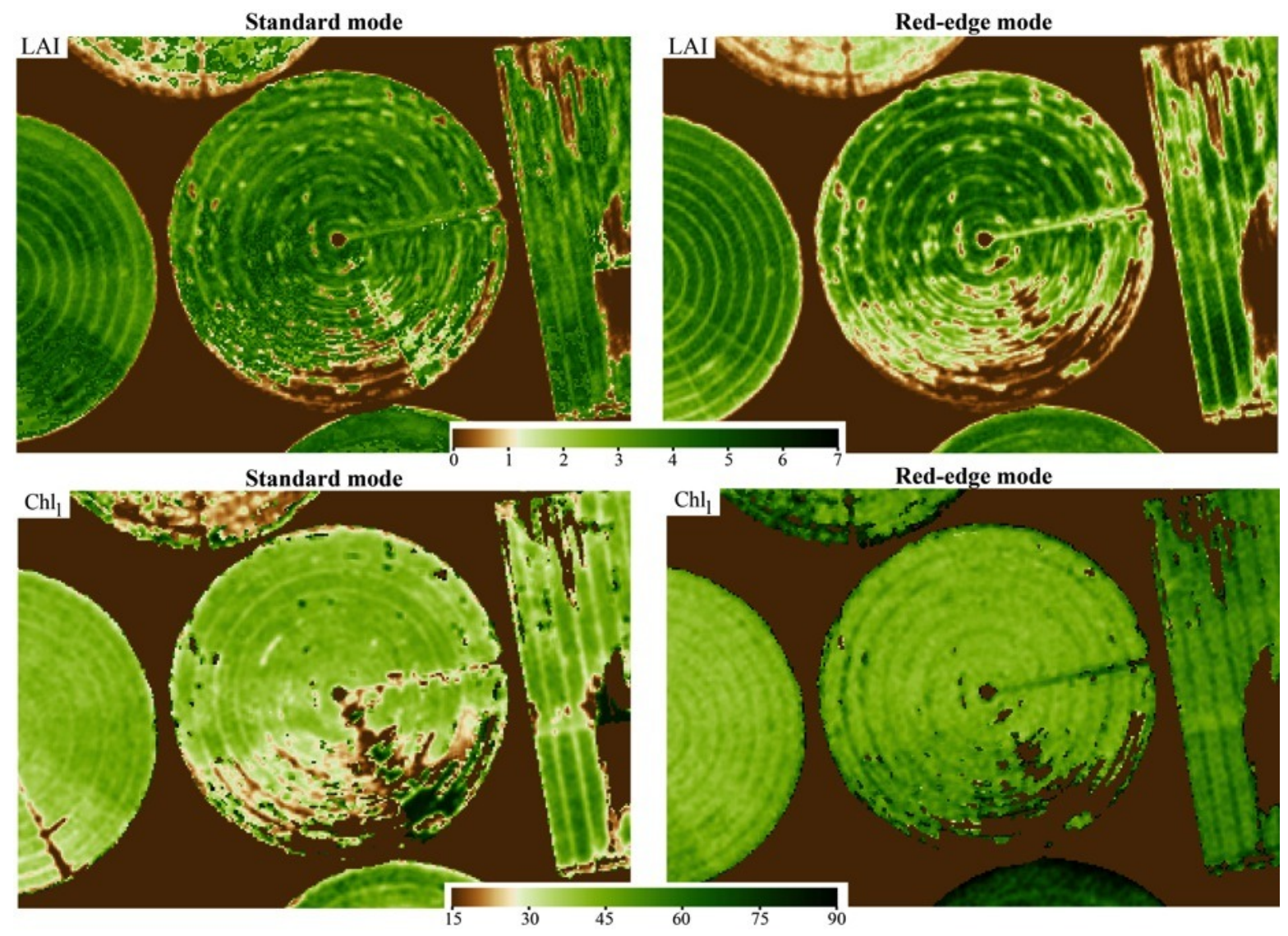

Figure 4. Maps of LAI $\left[\mathrm{m}^{2} \mathrm{~m}^{-2}\right]$ and $\mathrm{Chl}_{1}\left[\mu \mathrm{g} \mathrm{cm}^{-2}\right]$ on May 31, 2015 over a sub-section of the farm generated by REGFLEC with the standard and red-edge spectral configurations. The diameter of one pivot is approximately $1 \mathrm{~km}$.

maximal value and a relatively homogeneous intra-field distribution of $\mathrm{Chl}_{1}$, which is expected at this growth stage given sufficient water and nutrient availability ${ }^{33}$. Still, notable differences are evident between the standard and red-edge retrievals both in terms of magnitudes and spatial distribution. Artifacts are particularly visible in the standard mode retrievals, in part due to difficulties with properly discriminating LAI and $\mathrm{Chl}_{1}$ effects on observed reflectance spectra with the adopted spectral configuration. The red-edge based retrievals depict more realistic spatial patterns such as over the southeastern part of the center pivot. In both cases, artifacts in Chl tend to occur at the edges of the fields and over sparse covers where $\mathrm{Chl}_{1}$ retrieval is intrinsically uncertain ${ }^{15}$.

Validation results, based upon LAI and $\mathrm{Chl}_{1}$ measurements in fields of alfalfa, Rhodes grass, and corn over the three field campaigns, indicate total canopy chlorophyll (i.e., LAI x $\mathrm{Chl}_{1}$ ) retrieval with an overall root-mean-square-deviation (rmsd) of $0.95 \mathrm{~g} \mathrm{~m}^{-2}$ and $0.81 \mathrm{~g} \mathrm{~m}^{-2}$ for the standard (Figure 5a) and red-edge (Figure $5 \mathrm{~b}$ ) configuration, respectively. While REGFLEC reproduces the dynamics of in-situ measured canopy chlorophyll reasonably well in both cases, retrievals are underestimated by $45 \%$ (Figure 5a) and 35\% (Figure 5b), respectively. The low bias is particularly pronounced for alfalfa due to significant underestimations of the observed $\mathrm{Chl}_{1}\left(63 \pm 5.6 \mu \mathrm{g} \mathrm{cm}^{-2}\right)$ by the standard $(29 \pm 8.0$ $\left.\mu \mathrm{g} \mathrm{cm}^{-2}\right)$ and red-edge $\left(38 \pm 6.2 \mu \mathrm{g} \mathrm{cm}^{-2}\right)$ model. The red-edge model quite accurately predicts canopy chlorophyll for corn whereas the standard mode retrievals show an asymptotic behavior (Figure 5), which can be attributed to the greater sensitivity of the red-edge based predictive VIs (i.e., MTCI and $\mathrm{CI}_{\text {redge }}$ ) to changes in $\mathrm{Ch}_{1}$ and LAI over their full range (Figure 3). LAI validation statistics demonstrate added value of $\mathrm{CI}_{\mathrm{redge}}(\mathrm{rmsd}=1.23)$ over the exclusive use of EVI2 $(\mathrm{rmsd}=1.52)$ for LAI prediction.

The results demonstrate improved agreement with in-situ observations when red-edge information is incorporated into the modeling system. Still, large uncertainties prevail, which highlights significant challenges associated with the accurate retrieval of vegetation traits from remote sensing data when employing physically-based approaches. This may particularly be the case in extreme desert environments like this, where generally high aerosol loadings and dusty 
conditions introduce considerable uncertainty into the atmospheric correction of at-sensor radiances to surface reflectances. An additional complication relates to corrections for adjacency effects (i.e., radiation from the background and atmosphere scattered into the sensor field of view), which are maximized in dusty environments with large reflectance contrasts between a target pixel and its surrounding area ${ }^{24}$. REGFLEC adjusts model parameters iteratively to optimize the match between observed and modeled reflectances, and any issues in physical process descriptions or atmospheric correction will translate directly into the estimates of LAI and $\mathrm{Chl}_{1}$. A key objective in future field campaigns is the collection of field-based (e.g. ASD FieldSpec-4) top of canopy spectral reflectances concurrent with the remote sensing acquisitions for verification purposes.

\section{CONCLUSIONS}

Recent enhancements in spectral, spatial and temporal resolution of satellite sensors provide new opportunities to advance vegetation monitoring and characterization. A key objective is to exploit these advancements in sensor technologies to develop physically realistic, extendable and well-constrained techniques for accurately assessing plant biochemical and biophysical properties. In this study, red-edge information available from very high spatial resolution RapidEye data was integrated within a regularized canopy reflectance model inversion system in order to take advantage of the enhanced leaf chlorophyll and LAI sensitivity of red-edge based vegetation indices. Comparisons against a model setup with a standard spectral band configuration (i.e., red, green, near-infrared) demonstrated significantly improved performance when exploiting red-edge information within the retrieval system. Challenges remain in the proper separation of LAI and leaf chlorophyll effects on observed reflectance spectra, particularly for sparse cover conditions, and accurately correcting for atmospheric influences over desert environments.

\section{ACKNOWLEDGEMENTS}

Research reported in this publication was supported by the King Abdullah University of Science and Technology (KAUST). We greatly appreciate the logistical, equipment and scientific support offered to our team by Mr Jack King, Mr Alan King and employees of the Tawdeehiya Farm in Al Kharj, Saudi Arabia, without whom this research would not have been possible.

\section{REFERENCES}

[1] Houborg, R., Fisher, J.., Skidmore, A., “Advances in remote sensing of vegetation function and traits," Int. J. Appl. Earth Obs. Geoinf. (2015).

[2] Houborg, R., McCabe, M. F., Cescatti, A.., Gitelson, A. A., "Leaf chlorophyll constraint on model simulated Gross Primary Productivity in agricultural systems," Int. J. Appl. Earth Obs. Geoinf. (2015).

[3] Kaminski, T., Knorr, W., Scholze, M., Gobron, N., Pinty, B., Giering, R.., Mathieu, P.-P., "Consistent assimilation of MERIS FAPAR and atmospheric $\mathrm{CO}_{2}$ into a terrestrial vegetation model and interactive mission benefit analysis," Biogeosciences 9(8), 3173-3184 (2012).

[4] Robert, P. C., "Precision agriculture: A challenge for crop nutrition management," Plant Soil 247(1), 143-149 (2002).

[5] Moran, M. S., Inoue, Y.., Barnes, E. M., “Opportunities and limitations for image-based remote sensing in precision crop management," Remote Sens. Environ. 61(3), 319-346, Elsevier Science Inc (1997).

[6] Gitelson, A. A., Gritz, Y.., Merzlyak, M. N., "Relationships between leaf chlorophyll content and spectral reflectance and algorithms for non-destructive chlorophyll assessment in higher plant leaves.," J. Plant Physiol. 160(3), 271-282 (2003).

[7] Dash, J.., Curran, P. J., "Evaluation of the MERIS terrestrial chlorophyll index (MTCI),” Adv. Sp. Res. 39(1), 100-104 (2007).

[8] Homolová, L., Malenovský, Z., Clevers, J. G. P. W., García-Santos, G.., Schaepman, M. E., "Review of opticalbased remote sensing for plant trait mapping," Ecol. Complex. 15, 1-16 (2013). 
[9] Haboudane, D., Miller, J. R., Tremblay, N., Zarco-tejada, P. J.., Dextraze, L., "Integrated narrow-band vegetation indices for prediction of crop chlorophyll content for application to precision agriculture," Remote Sens. Environ. 81, 416-426 (2002).

[10] Combal, B., Baret, F., Weiss, M.., Trubuil, A., "Retrieval of canopy biophysical variables from bidirectional reflectance: Using prior information to solve the ill-posed inverse problem," Remote Sens. Environ. 84, 1-15 (2002).

[11] Baret, F., "Vegetation canopy reflectance: Factors of variation and application for agriculture," [Physical measurements and signatures in remote sensing], D. Hunt, Ed., Courchevel, France, 145-167 (1991).

[12] Houborg, R., Soegaard, H.., Boegh, E., "Combining vegetation index and model inversion methods for the extraction of key vegetation biophysical parameters using Terra and Aqua MODIS reflectance data," Remote Sens. Environ. 106(1), 39-58 (2007).

[13] Dorigo, W., Richter, R., Baret, F., Bamler, R.., Wagner, W., "Enhanced Automated Canopy Characterization from Hyperspectral Data by a Novel Two Step Radiative Transfer Model Inversion Approach," Remote Sens. 1(4), 1139-1170 (2009).

[14] Atzberger, C.., Richter, K., "Spatially constrained inversion of radiative transfer models for improved LAI mapping from future Sentinel-2 imagery," Remote Sens. Environ. 120, 208-218, Elsevier Inc. (2012).

[15] Houborg, R., McCabe, M., Cescatti, A., Gao, F., Schull, M.., Gitelson, A., "Joint leaf chlorophyll content and leaf area index retrieval from Landsat data using a regularized model inversion system (REGFLEC)," Remote Sens. Environ. 159, 203-221, Elsevier Inc. (2015).

[16] Houborg, R.., Anderson, M. C., "Utility of an image-based canopy reflectance modeling tool for remote estimation of LAI and leaf chlorophyll content at regional scales," J. Appl. Remote Sens. 3(1), 033529 (2009).

[17] Houborg, R.., Boegh, E., "Mapping leaf chlorophyll and leaf area index using inverse and forward canopy reflectance modeling and SPOT reflectance data," Remote Sens. Environ. 112(1), 186-202 (2008).

[18] PME., "Surface annual climatological report"," 2009, <http://www.pme.gov.sa/Riyadh Old.htm> (27 May 2014 ).

[19] Houborg, R., Cescatti, A., Migliavacca, M.., Kustas, W. P., "Satellite retrievals of leaf chlorophyll and photosynthetic capacity for improved modeling of GPP," Agric. For. Meteorol. 177, 10-23, Elsevier B.V. (2013).

[20] Kobayashi, H., Ryu, Y., Baldocchi, D. D., Welles, J. M.., Norman, J. M., "On the correct estimation of gap fraction: How to remove scattered radiation in gap fraction measurements?," Agric. For. Meteorol. 174-175, 170-183 (2013).

[21] Cerovic, Z. G., Masdoumier, G., Ghozlen, N. Ben., Latouche, G., "A new optical leaf-clip meter for simultaneous non-destructive assessment of leaf chlorophyll and epidermal flavonoids.," Physiol. Plant. 146(3), 251-260 (2012).

[22] Kotchenova, S. Y., Vermote, E. F., Matarrese, R.., Klemm, F. J., "Validation of a vector version of the 6 S radiative transfer code for atmospheric correction of satellite data. Part I: path radiance.," Appl. Opt. 45(26), 6762-6774 (2006).

[23] D’Almeida, G. A., Koepke, P.., Shettle, E. P., Atmospheric aerosols. Global climatology and radiative characteristics, 561 (1991).

[24] Richter, R., Bachmann, M., Dorigo, W.., Muller, A., "Influence of the Adjacency Effect on Ground Reflectance Measurements," IEEE Geosci. Remote Sens. Lett. 3(4), 565-569 (2006).

[25] Vermote, E. F., Tanre, D., Deuze, J. L., Herman, M.., Morcette, J.-J., "Second Simulation of the Satellite Signal in the Solar Spectrum, 6S: an overview," IEEE Trans. Geosci. Remote Sens. 35(3), 675-686 (1997).

[26] Verhoef, W., "Light scattering by leaf layers with application to canopy reflectance modeling: The SAIL model," Remote Sens. Environ. 16(2), 125-141 (1984).

[27] Verhoef, W.., Bach, H., "Coupled soil-leaf-canopy and atmosphere radiative transfer modeling to simulate hyperspectral multi-angular surface reflectance and TOA radiance data," Remote Sens. Environ. 109(2), 166182 (2007).

[28] Jacquemoud, S.., Baret, F., "PROSPECT: A model of leaf optical properties spectra," Remote Sens. Environ. 34, 75-91 (1990).

[29] Feret, J.-B., François, C., Asner, G. P., Gitelson, A. A., Martin, R. E., Bidel, L. P. R., Ustin, S. L., le Maire, G.., Jacquemoud, S., "PROSPECT-4 and 5: Advances in the leaf optical properties model separating photosynthetic pigments," Remote Sens. Environ. 112(6), 3030-3043, Elsevier Inc. (2008). 
[30] Jiang, Z., Huete, A., Didan, K.., Miura, T., "Development of a two-band enhanced vegetation index without a blue band," Remote Sens. Environ. 112(10), 3833-3845 (2008).

[31] Huete, A., Didan, K., Miura, T., Rodriguez, E. P., Gao, X.., Ferreira, L. G., "Overview of the radiometric and biophysical performance of the MODIS vegetation indices," Remote Sens. Environ. 83, 195-213 (2002).

[32] Viña, A., Gitelson, A. A., Nguy-Robertson, A. L.., Peng, Y., "Comparison of different vegetation indices for the remote assessment of green leaf area index of crops," Remote Sens. Environ. 115(12), 3468-3478, Elsevier Inc. (2011).

[33] Gitelson, A. A., Peng, Y., Arkebauer, T. J.,, Schepers, J., "Relationships between gross primary production, green LAI, and canopy chlorophyll content in maize: Implications for remote sensing of primary production," Remote Sens. Environ. 144, 65-72, Elsevier Inc. (2014). 